\title{
LACERAÇÃO DE TRAQUEIA EM UM CÃO - RELATO DE CASO
}

\author{
José Edgard de Oliveira ALVES ${ }^{1 *}$, Larissa Pim CALABREZ ${ }^{1}$ \& Dévanny Weller Ferreira MENASSA ${ }^{2}$
}

1 Universidade Estadual do Norte Fluminense, Campos dos Goytacazes, RJ, Brasil.

2 MedicalPet Hospital Veterinário, Campos dos Goytacazes, RJ, Brasil.

*Autor para correspondência: edgardoliveiraalves@ hotmail.com

http://dx.doi.org/10.18571/acbm.115

\section{RESUMO}

As lesões traqueais, apesar de incomuns em animais de companhia, merecem atenção especial na clínica de pequenos animais, uma vez que, de acordo com a gravidade, podem causar risco iminente de morte aos pacientes acometidos. Estas lesões podem ocorrer por mecanismos contusos ou penetrantes, sendo mais frequentemente associadas a lacerações decorrentes de mordeduras, projéteis, variados tipos de trauma e, inclusive, de forma iatrogênica. $\mathrm{O}$ tratamento pode ser conservador ou cirúrgico, sendo a escolha entre eles dependente da apresentação clínica do paciente, como a ocorrência de comorbidades e estabilidade ventilatória frente à laceração da via aérea. O presente artigo relata o caso de uma cadela diagnosticada com laceração traqueal decorrente de mordedura de outro cão, submetida ao tratamento conservador com sucesso terapêutico. Conclui-se que um exame clínico minucioso no acompanhamento da evolução do quadro pode ser utilizado como critério confiável para a decisão quanto à conduta conservadora ou cirúrgica, e que o tratamento expectante é satisfatório para pacientes que não apresentem alterações respiratórias.

Palavras-chave: Via Aérea; Sistema Respiratório; Trauma; Enfisema; Lesão por Mordedura.

\begin{abstract}
Tracheal laceration in a dog - Case report. The tracheal lesions, although rare in companion animals, deserve special attention in clinical of small animals, since, according to the severity, can cause imminent risk of death to affected patients. These injuries can occur by blunt or penetrating mechanisms, more frequently associated with lacerations resulting from bites, bullets, various types of trauma, and including atrogenic form. Treatment can be conservative or surgical and the choice between them depends of the clinical presentation of the patient, as the occurrence of comorbidities and ventilatory stability to the airway laceration. This article reports the case of a dog diagnosed with tracheal laceration caused by biting of another dog, subjected to conservative treatment with therapeutic success. It concludes that a detailed clinical examination to monitor the evolution of the clinical condition can be used as a reliable criterion for the decision to the conservative or surgical management, and that the expectant treatment is suitable for patients without respiratory alterations.
\end{abstract}

Keywords: Airway; Respiratory System; Trauma; Emphysema; Bite Wound.

\section{Introdução}

A traqueia é um tubo flexível, semirrígido, que se estende da cartilagem cricóide ao brônquio principal, formada por cerca de 35 a 45 cartilagens hialinas em formato de $\mathrm{C}$ incompletas, unidas ventral e lateralmente por ligamentos anulares e dorsalmente pela membrana traqueal dorsal (MACPHAIL, 2015a), responsável por prover o ar até os pulmões através de seu lúmen (SCHNEIDER; OLSSON, 2013). 
Os mecanismos que envolvem as lesões traqueais podem ser divididos em contusos (que incluem lesões por esmagamento ou estrangulamento) e penetrantes (PEREIRA et al., 2011). Perfurações traumáticas na traqueia não são comuns em pequenos animais, mas podem ocorrer como resultado de feridas por mordeduras no pescoço, acidentes com projéteis de arma de fogo, atropelamentos, de forma iatrogênica no lavado traqueal, na superinsuflação de cuffs em tubos endotraqueais, na punção de veia jugular, em associação com trauma torácico ou durante ou após procedimentos cirúrgicos envolvendo a traqueia (KIRPENSTEJIN; HAAR, 2006).

Não existem dados epidemiológicos sobre a incidência de injúrias traqueais e tipos de traumas associados na clínica de pequenos animais, contudo, em medicina humana, os traumatismos penetrantes de traqueia possuem maior incidência. Cerca de $21 \%$ dos pacientes acometidos por lesão traumática de via aérea superior não sobrevivem às primeiras 2 horas de internação hospitalar (PEREIRA et al., 2011). Em cães e gatos, as alterações clínicas podem aparecer desde horas a dias após o trauma inicial e incluem, mais frequentemente, taquipneia, dispneia e enfisema subcutâneo, podendo ou não estar presente pneumotórax ou pneumomediastino (SCOTT et al., 2006). Embora orifícios traqueais pequenos possam se resolver sem a necessidade de intervenção cirúrgica (LEAL et al., 2013), pacientes instáveis com ameaça imediata à vida, requerem rápido controle das vias aéreas por qualquer método imediatamente disponível, sendo esta manobra essencial para garantia da vida e sobrevida do paciente (PEREIRA et al., 2011). Portanto, apesar de raros, casos de laceração traqueal, representam potencial risco de vida aos pequenos animais, sendo considerados casos emergenciais. A eficiência na detecção precoce dos sinais clínicos e estabilização do paciente com uso de técnicas terapêuticas adequadas são de fundamental importância para a sobrevida do animal (LEAL et al., 2013).

Diante do exposto, o presente trabalho teve como objetivo abordar os aspectos fisiopatológicos do trauma de pescoço e traqueia e relatar um caso de laceração traqueal por mordedura com resolução clínica em um cão.

\section{Relato de Caso}

Uma cadela, sem raça definida, de 7 anos de idade e pesando $6,7 \mathrm{~kg}$, foi apresentada após briga com outro cão onde se observavam múltiplas lesões por mordedura, especialmente na região cervical (figura 1). O animal apresentava-se consciente e responsivo, eupneico, com mucosas acianóticas, porém levemente hipocoradas, frequência cardíaca de $140 \mathrm{bpm}$, sem estertores à ausculta do tórax e da traqueia e com discreta hemorragia nos ferimentos cutâneos provocados pelas mordeduras. 


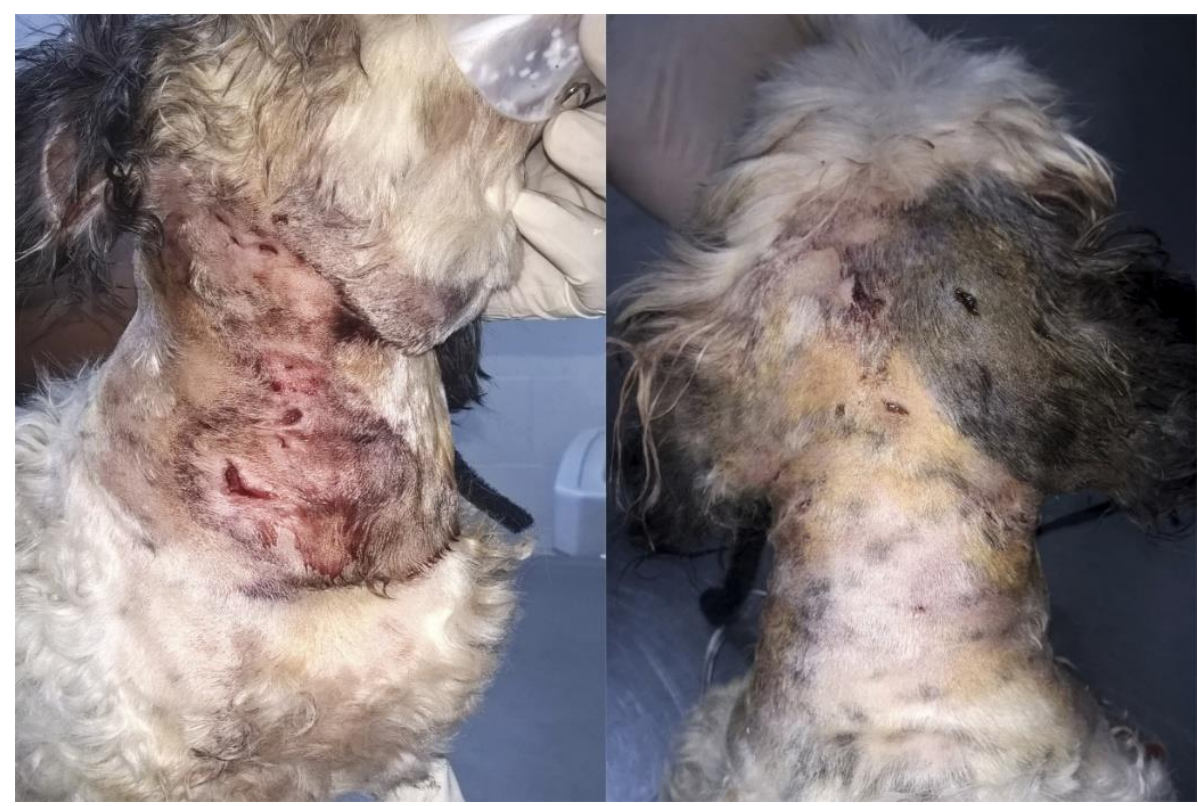

Figura 1. Animal apresentando múltiplas lesões por mordedura na região de pescoço e cabeça.

Durante a manipulação para tricotomia e antissepsia das lesões cutâneas, quando houve maior agitação do animal e hiperpneia em função do estresse e da dor na região afetada pelo trauma, percebeu-se a formação de bolsões subcutâneos na região ventral cervical com escape de ar através dos ferimentos, diagnosticando-se o quadro de laceração traqueal por trauma penetrante. Diante da possibilidade de ocorrência de pneumotórax associado à lacerações em traqueia, procedeu-se a toracocentese exploratória, constatando-se o não comprometimento da pressão negativa intrapleural.

$\mathrm{O}$ animal foi internado e medicado com ácido tranexâmico na dose de $50 \mathrm{mg} / \mathrm{kg}$ por via intravenosa (IV) e, posteriormente, com $25 \mathrm{mg} / \mathrm{kg}$, IV, QID, durante 24 horas. Foram aplicadas, ainda, compressas frias para hemostasia nas lesões. Foi instituída terapia com tramadol (4 mg/kg, IV, TID), meloxicam (0,1 mg/kg, IV, SID), dipirona (25 mg/kg, IV, BID) e ceftriaxona $40 \mathrm{mg} / \mathrm{kg}$, IV, BID) e tratamento tópico das lesões com iodopovidona (Povidine ${ }^{\circledR}$ ) e pomada a base de gentamicina, sulfanilamida, sulfadiazina, ureia e vitamina A (Vetaglós ${ }^{\circledR}$ ).

O animal apresentou enfisema subcutâneo na região ventral do pescoço. Optou-se, então, pela realização de uma bandagem compressiva no pescoço visando reduzir o espaço morto subcutâneo e, consequentemente, a formação de enfisema. Após 24 horas, observava-se a ocorrência de enfisema subcutâneo localizado na região ventral da mandíbula e na parte dorsal da cabeça. Diante disso, a bandagem foi expandida também para a região da cabeça. O enfisema evoluiu para uma formação discreta na região direita do tórax, mais concentrada na região axilar. Expandiu-se a bandagem compressiva para, além de pescoço e cabeça, a região torácica. Após 36 horas não foi notado aumento do enfisema subcutâneo em nenhuma das regiões antes verificadas.

O animal recebeu alta após 48 horas de internação, com evolução clínica favorável e sem alterações respiratórias, sob recomendação de retorno após 24 horas para reavaliação do quadro clínico. O tratamento pós-hospitalar foi realizado com tramadol (4 mg/kg, VO, TID, por 5 dias), meloxicam (0,1 mg/kg, VO, SID, por 3 dias), dipirona (25 mg/kg, VO, BID, por 3 dias), cefalexina (30 mg/kg, VO, BID, por 8 dias), metronidazol (25 mg/kg, VO, BID, por 7 dias) e manutenção da bandagem compressiva. O enfisema subcutâneo diminuiu progressivamente e a remissão total ocorreu no quinto dia após o trauma. A cicatrização completa das lesões cutâneas se deu no décimo dia de tratamento. 


\section{Discussão}

Segundo Scott et al. (2006), o diagnóstico de laceração traqueal deve ser realizado com base no histórico e no quadro clínico apresentado e em exames complementares, tais como radiografia torácica e cervical e hemogasometria. A traqueoscopia é considerada o método de escolha para avaliar a localização e a dimensão da ruptura de traqueia. A tomografia computadorizada pode ser indicada caso seja necessária uma avaliação pré-operatória mais detalhada, especialmente quando o trauma envolve também a laringe (KIRPENSTEIJIN; HAAR, 2006). No entanto, nem sempre se tem disponibilidade da realização imediata de tais exames. Por este motivo, um exame clínico minucioso deve ser feito para determinar uma terapêutica adequada. No animal em questão, o enfisema subcutâneo se iniciou de maneira gradativa. A formação de bolsão subcutâneo e escape de ar pelos ferimentos só ocorreram nos momentos de estresse do animal e quando o mesmo permanecia em repouso não se percebiam alterações, com exceção do enfisema subcutâneo. A ausência de tosse e de sons crepitantes à ausculta da traqueia reforça a tese de que a perfuração traqueal neste caso era pequena, pois, uma vez que havia sangramento nos tecidos adjacentes, tem-se a hipótese de que ocorreria aspiração de sangue para o lúmen traqueal, caso a laceração fosse grande. Em alternativa à radiografia torácica para avaliação de pneumotórax e na indisponibilidade de um exame radiográfico de emergência, optou-se pela toracocentese exploratória com scalp conectado a um dispositivo de três vias e seringa para descartar a possibilidade de pneumotórax associado, constatando-se a integridade na pressão negativa intrapleural.

O tratamento da laceração traqueal pode ser cirúrgico ou conservador (MEDINA et al., 2009). Segundo Scott et al. (2006), a terapia de suporte no tratamento conservador inclui restrição de espaço e atividade, oxigenoterapia e drenagem intermitente ou contínua em caso de pneumotórax associado. Essas manobras permitem manter o animal estável até a cicatrização da lesão, porém a resolução poderá ser mais tardia, levando de 2 a 10 dias. Ainda segundo o mesmo autor, a ocorrência de dispneia não responsiva à oxigenoterapia indica falha no tratamento conservativo e é um indicador para a cirurgia. A intervenção cirúrgica foi utilizada em situação semelhante por Leal et al. (2013), onde houve histórico de briga com outro cão. Os autores consideraram que, apesar do orifício traqueal ser pequeno, a evolução negativa do quadro, com taquipneia progressiva e enfisema subcutâneo por todo o corpo, foi determinante para guiar a conduta. No presente estudo de caso, a manutenção da estabilidade respiratória do paciente foi o principal indicador de um prognóstico favorável e critério determinante pela escolha de um tratamento conservador. Em outro caso de perfuração traqueal por mordedura, Shneider e Olsson (2013) indicaram a cirurgia para correção de uma laceração no sentido vertical medindo $2 \mathrm{~cm}$ na traqueia de um cão de $15 \mathrm{~kg}$, o qual apresentava alterações respiratórias relevantes, tais como taquipneia e angústia respiratória.

Até o século XX, acreditava-se que a cicatrização da traqueia e dos brônquios ocorria de forma ineficiente. Tal crença embasava-se na observação da escassa vascularização cartilaginosa e da tensão na linha de anastomose, no caso de suturas término-terminais (BONOMI, 2011). Entretanto, MacPhail (2015a) cita que a cicatrização na traqueia se inicia em até duas horas após a lesão das células superficiais. As células colunares ciliadas intactas na periferia do ferimento se achatam, perdem seus cílios e migram sobre a lesão e, em 48 horas, tem início a mitose do epitélio basal e das células colunares ciliadas. Ainda segundo este autor, a organização e a diferenciação celulares começam 4 dias após o trauma. Essas informações são particularmente importantes no paciente sem alterações respiratórias e com formação de enfisema subcutâneo, pois sustentam a tese de que o enfisema por si só não determina se a conduta deve ser cirúrgica ou não, uma vez que poderá ocorrer escape de ar pelo orifício da laceração até que ocorra a cicatrização total do ferimento. De acordo com as informações supracitadas, o caso clínico discutido neste trabalho evoluiu de maneira similar, com redução gradativa do enfisema subcutâneo e remissão total após 
5 dias da ocorrência do trauma. Em humanos, Medina et al. (2013) relatam 3 casos de laceração traqueal após intubação endotraqueal, dentre os quais apenas um foi tratado de maneira conservadora. Segundo os autores, o paciente evoluiu com melhora do enfisema subcutâneo e, decorridos 8 dias da lesão, em nova avaliação por broncoscopia foi constatada a cicatrização completa da laceração.

No presente relato, após a alta da internação e liberação do animal para continuidade do tratamento pós-hospitalar, observou-se no primeiro retorno (72 horas após o trauma) a redução do enfisema subcutâneo. Ainda assim, optou-se por manter a bandagem compressiva por mais 48 horas. A bandagem compressiva foi removida assim que se constatou a remissão do enfisema subcutâneo, em avaliação realizada no quinto dia após o trauma. Um período um pouco mais prolongado até a involução das alterações foi descrito por Leal et al. (2013), que relatam que, após intervenção cirúrgica, a taquipneia e o enfisema subcutâneo decorrentes de laceração traqueal por mordedura diminuíram progressivamente e ao final de 10 dias de pós operatório não se observava nenhuma alteração clínica.

A antibioticoterapia inicial com ceftriaxona e, posteriormente, com cefalexina é sustentada por MacPhail (2015a), que destaca entre os antibióticos frequentemente indicados para afecções do trato respiratório superior a ampicilina, fluoroquinolonas, cefalosporinas, doxiciclina, azitromicina e sulfonamidas potencializadas. Pavletic e Trout (2006), citam as cefalosporinas, incluindo a cefalexina, como agentes geralmente efetivos contra Pasteurella spp. e uma variedade de outros microorganismos no tratamento de lesões por mordeduras em pequenos animais. Ainda neste tipo de lesão, além da contaminação oriunda da flora oral do animal agressor, o tecido desvitalizado, o espaço morto, o comprometimento no fluxo sanguíneo local e o acúmulo de soro formam um ambiente propício para o crescimento bacteriano, inclusive para bactérias anaeróbicas (MACPHAIL, 2015b). Essa informação respalda a inclusão do metronidazol na antibioticoterapia combinada.

Assim, espera-se que o presente relato de caso possa contribuir para situações clínicas semelhantes, em que não se tenha a disponibilidade imediata de exames complementares de imagem e a conduta terapêutica deva ser guiada exclusivamente por uma avaliação clínica detalhada do paciente.

\section{Conclusão}

Conclui-se que a avaliação clínica pode ser tomada como critério confiável para tomadas de decisão com relação à conduta no paciente com laceração de traqueia por mordedura e que o tratamento conservador se mostrou satisfatório para pacientes com sinais clínicos brandos, sem apresentar alterações respiratórias. Exames como a radiografia e a traqueoscopia podem ser desejáveis nos casos de perfurações com sinais clínicos mais severos, para determinar o local exato e a extensão da lesão e, consequentemente, definir a conduta clínica ou cirúrgica a ser aplicada.

\section{Referências}

BONOMI, D. O. Cicatrização de anastomoses traqueais após uso tópico de Mitomicina C em ratos. 2011. 39 f. Dissertação (Mestrado em ciências aplicadas à cirurgia e à oftalmologia) Universidade Federal de Minas Gerais - UFMG, Belo Horizonte, 2011.

KIRPENSTEIJIN, J.; HAAR, G. T. Tracheal trauma: Fixing it. Proceedings of the North American Veterinary Conference - Small Animal Edition, v. 20, 2006. p. 1413-1414.

LEAL, L. M.; LIMA, T. B.; DAL PIETRO, N. H. P. S.; DIOGO, L. M. I.; DE NARDI, A. B.; MINTO, B. W. Ruptura de traqueia traumática em cão - Relato de caso. In: XI CONPAVET 
- Congresso Paulista das Especialidades, n. 11, São Paulo. Resumos... São Paulo: Revista de Educação Continuada em Medicina Veterinária e Zootecnia, v. 11, n. 2, p. 76-77.

MACPHAIL, C. M. Cirurgia do sistema respiratório superior. In: FOSSUM, T. W. Cirurgia de pequenos animais, 4 ed., Rio de Janeiro: Elsevier, 2015a. p. 906-957.

MACPHAIL, C. M. Cirurgia do sistema tegumentar. In: FOSSUM, T. W. Cirurgia de pequenos animais, 4 ed., Rio de Janeiro: Elsevier, 2015b. p. 190-288.

MEDINA, C. R.; CAMARGO, J. J.; FELICETTI, J. C.; MACHUCA, T. N.; GOMES, B. M.; MELO, I. A. Laceração traqueal pós-intubação: Análise de três casos e revisão de literatura. Jornal Brasileiro de Pneumologia, v. 35, n. 8, p. 809-813, 2009.

PAVLETIC, M. M.; TROUT, N. J. Bullet, bite and burn wounds in dogs and cats. Veterinary Clinics of North America: Small Animal Practice, v. 36, n. 4, p. 873-893, 2006.

PEREIRA, B. M. T.; CASSIN, W. S.; FIORELLI, R. K. A. Trauma de laringe e traqueia. In: ANDREOLlO, N. A.; AQUINO, J. L. B.; MARTINEZA, C. A. R. Atualidades em Clínica Cirúrgica: Intergastro e Trauma - 2011. 2 ed. Rio de Janeiro: Atheneu, 2011. p. 75-87.

SCHNEIDER, D. J.; OLSSON, D. C. Ruptura de traqueia por mordedura com lesão vertical em um cão. In: III MIC - Mostra de Iniciação Científica, 2013. Concórdia. Resumos... Concórdia: IFC - Instituto Federal Catarinense, 2013. Disponível em: http://anaismic.concordia.ifc.edu.br/anais/2013. Acesso em 18 de out. 2016.

SCOTT, K.; HARDIE, E.; MARKS, S. L. Tracheal lacerations. Standards of care: Emergengy and crirical care medicine, v. 8, n. 11, 2006. p. 1-4. 